\title{
A regime analysis of Atlantic winter jet variability applied to evaluate HadGEM3- GC2
}

Article

Accepted Version

Masato, G., Woollings, T., Williams, K. D., Hoskins, B. J. and Lee, R. W. (2016) A regime analysis of Atlantic winter jet variability applied to evaluate HadGEM3-GC2. Quarterly Journal of the Royal Meteorological Society, 142 (701). pp. 3162-3170. ISSN 1477-870X doi:

https://doi.org/10.1002/qj.2897 Available at https://centaur.reading.ac.uk/68061/

It is advisable to refer to the publisher's version if you intend to cite from the work. See Guidance on citing.

To link to this article DOI: http://dx.doi.org/10.1002/qj.2897

Publisher: Royal Meteorological Society

All outputs in CentAUR are protected by Intellectual Property Rights law, including copyright law. Copyright and IPR is retained by the creators or other copyright holders. Terms and conditions for use of this material are defined in the End User Agreement. 


\section{CentAUR}

Central Archive at the University of Reading

Reading's research outputs online 


\title{
A regime analysis of Atlantic winter jet variability applied to evaluate HadGEM3-GC2
}

\author{
G. Masato, T. Woollings*, K. D. Williams, B. J. Hoskins and R. W. Lee \\ Department of Meteorology, University of Reading, Earley Gate, PO Box 243, Reading, RG6 6BB, UK \\ ${ }^{*}$ Correspondence to: tim.woollings @ physics.ox.ac.uk
}

\begin{abstract}
The behaviour of the eddy-driven jet over the Atlantic sector during the winter season is analysed for the ERA-Interim reanalysis and the coupled and atmosphere-only configuration of HadGEM3-GC2 - the climate model in use at the Met Office. The tri-modal distribution that reveals the jet-stream structure in terms of its preferred locations is reproduced with good accuracy by the model, although a distinct bias towards the high-latitude position is observed. Two different scenarios are found to contribute to this bias. One occurs when the jet shifts from its southern regime, whereby it settles too far north and for too long compared to the reanalysis. The other is associated with the exit from the central latitude regime, with too many events shifting poleward rather than equatorward. Excessively large lower tropospheric eddy heat fluxes during these transitions may account for the jet errors, even though the heat fluxes do not exhibit a climatological bias. Interestingly, these biases are weaker when the atmosphere model is forced with observed SSTs, suggesting that either it is vital to have the correct SST distribution or that ocean-atmosphere coupling plays a key role in the biases. Additional analysis revealed that the Pacific jet exit is biased south in the coupled model and that this is likely to contribute to the Atlantic bias. Anomalously warm SSTs in the Gulf Stream region may be acting together with the Pacific bias in fostering the anomalous activity in the low level eddy heat fluxes.

Key Words: Jet-stream; regimes; HadGEM3-GC2

Received...
\end{abstract}

1. Introduction

The Atlantic jet-stream variability has long been a critical topic of research. Its importance in modulating the weather over the
Euro-Atlantic sector from daily to seasonal and inter-annual time scales is widely recognised, and several papers have investigated such connections (e.g. Mahlstein et al. 2012; Trigo et al. 2002).

This article has been accepted for publication and undergone full peer review but has not been through the copyediting, typesetting, pagination and proofreading process, which may lead to differences between this version and the Version of Record. Please cite this article as doi: 10.1002/qj.2897

This article is protected by copyright. All rights reserved. 


\section{G. Masato et al}

Another important strand of publications has dealt with the grade of fidelity of the general circulation models in reproducing the jet-stream behaviour. It is well known that the models have difficulty in simulating correctly the eddy-driven jet, whereby it tends to be too far equatorward and too strong (e.g. Hannachi et al. 2013). At present there are still large deficiencies, for example the vast majority of the CMIP5 models (Taylor et al. 2012) largely fail in simulating the tri-modal distribution of the jet latitude (Anstey et al. 2013). This behaviour is unique to the Atlantic eddy-driven jet. Woollings et al. (2010) were the first to explicitly describe it, then in following papers the transitions between the three different jet regimes (the northern, central and southern regime) were analysed in detail (e.g. Franzke et al. 2011). The Met Office climate model used for the IPCC Fifth Assessment Report (Collins et al. 2008) is indeed an exception to this, inasmuch as it is able to reproduce the three-state jet quite well. Nevertheless, it still suffers from a large bias related to the high latitude regime, which is too populated compared to the central latitude regime, unlike the reanalysis (see dashed magenta line in Fig. 3a in Anstey et al. 2013). Interestingly, a similar A Issue is still present in the latest version of the global coupled model in use at the Met Office (Williams et al. 2014), with no notable changes from the previous operational configuration (HadGEM2). This bias to overpopulate the high-latitude regime is in stark contrast to the historical bias of an overly zonal flow.

\section{(1)}

One method we use here to investigate the biases is the eddy-mean flow interaction approach, whereby the jet variability is understood as forced by the interaction with the synoptic systems. This framework has been invoked in several papers to explain the jet stream behaviour and its fluctuations over different time scales, as well as the different time persistence within a given state (Lorenz and Hartmann 2001; Barnes et al. 2010). Barotropic (e.g. Yu and Hartmann 1993) as well as baroclinic (e.g. Gerber and Vallis 2007) theories have been developed to describe the eddy-driven jet behaviour. In particular, the latter have invoked the generation of baroclinicity as the main driver for such changes (Thompson and Birner 2012; Novak et al. 2015), whereby this process leads to the increase of lower tropospheric This article is protected by copyright. All rights reserved.

tropospheric wave activity out of the jet and concurrent westerly momentum flux into the jet.

Our aim is to understand the biases in the lower tropospheric zonal wind and hence we focus on analysis of the transient baroclinic eddy effects. Since these are primarily responsible for barotropising the flow and accelerating the low-level wind (Hoskins et al. 1983) we hypothesise that biases in the zonal wind are likely to be accompanied by biases in the transient eddy characteristics. We apply some new diagnostics to describe the biases in the jet and the eddies, focussing on the regime structure of the jet and the magnitude and orientation of eddy fluxes. These are intended to provide some physical insight and to complement existing methods such as a full decomposition of the vorticity budget, as has been used very successfully by Barnes and Hartmann (2010) for example. In section 5 we also consider the role of more remote processes, in particular Pacific jet biases. These are suggested to influence the Atlantic jet by modulating the behaviour of the transients as they enter the Atlantic sector.

The paper is divided as follows, section 2 describes the methodology and the data used. Section 3 highlights the general results and the main biases of the model in simulating the eddydriven jet, while section 4 describes the process-based analysis employed in this study and applies it to the reanalysis. The jet bias is further investigated by looking at the jet transitions in section 5 . The concluding remarks are presented in section 6 .

\section{Data and Diagnostics}

The data sources are the ERA-Interim reanalysis (ERA-I - Dee et al. 2011) and the Global Coupled model 2.0 (GC2 - Williams et al. 2014). The Global Atmosphere 6.0 (GA6.0 - Walters et al. 2014) component is used for the atmosphere-only configuration (here named GC2-A). In this version of the model the ENDGame dynamical core has been introduced. This is an evolution of the previous dynamical core and is based on a semi-implicit, semi-Lagrangian discretization of the governing equations. The period used is 1980-2012 for the reanalysis and 28 years for the model versions. These are Present Day control simulations with forcings fixed at year 2000 levels. The ERA-I grid-resolution is $1.5^{\circ} \times 1.5^{\circ}$, the atmosphere component horizontal resolution is 
N216, while for the coupled version the ocean component uses

the 0.25 degree horizontal resolution. The fields downloaded have been interpolated to the reanalysis grid-resolution before applying any post-processing. To produce and post-process the data, the following fields have been used: $(u, v)$ (the wind field) at 250, 850 $\mathrm{hPa}$ and temperature at $850 \mathrm{hPa}$.

The data analysis has been conducted using a process-based approach, in particular the eddy fluxes and their impact onto the Jet have been analysed in detail. To do that, the E-vector diagnostic has been employed (Hoskins et al. 1983). The E-vector has been derived for the high-pass time-filtered eddies only (i.e. with period shorter than 10 days) using the Lanczos method (Duchon 1979). Here, a particular focus has been given to the third component of the quasi-vector, which can be associated with the low-level eddy heat fluxes. The horizontal components relate to the momentum flux in the upper troposphere. The three diagnostics can be written as follows:

$E p=f \frac{\overline{v^{\prime} \theta^{\prime}}}{\Theta_{p}} ;$
$E \mid=\sqrt{E_{x}^{2}+E_{y}^{2}} \quad, E d=\arctan \left(\frac{E_{y}}{E_{x}}\right)$

where $E_{x}=\overline{v^{\prime 2}-u^{\prime 2}}$ and $E_{y}=-\overline{u^{\prime} v^{\prime}}$, while $u^{\prime}$ and $v^{\prime}$ are the high-pass filtered winds, $f$ is the Corliolis parameter, and $\Theta_{p}$ is a standard vertical profile of potential temperature. $|E|$ represents the strength of the fluxes, while $E d$ is used to detect their direction (positive and negative values are for poleward and equatorward propagation, respectively). It is also noted that $E p$ is normalised following Brayshaw et al. (2008), whereby Ep is multiplied by $\chi \Delta p)^{-1}$, where $\Delta p=150 \mathrm{hPa}$ and $\lambda=1.7 \times 10^{-5} s^{-1}$ (see the appendix in their paper for further details). The normalised $E p$ is measured in $\mathrm{m} / \mathrm{s}$, so that $E p$ and the divergence of $E$ are then comparable.

The divergence of the horizontal component of the E-vector $(\nabla \cdot E)$ is commonly used rather than its modulus to describe the eddy momentum fluxes at the upper levels (see Hoskins et al. 1983, for its interpretation), however here $|E|$ has been chosen as it is less noisy than the former. A more detailed interpretation
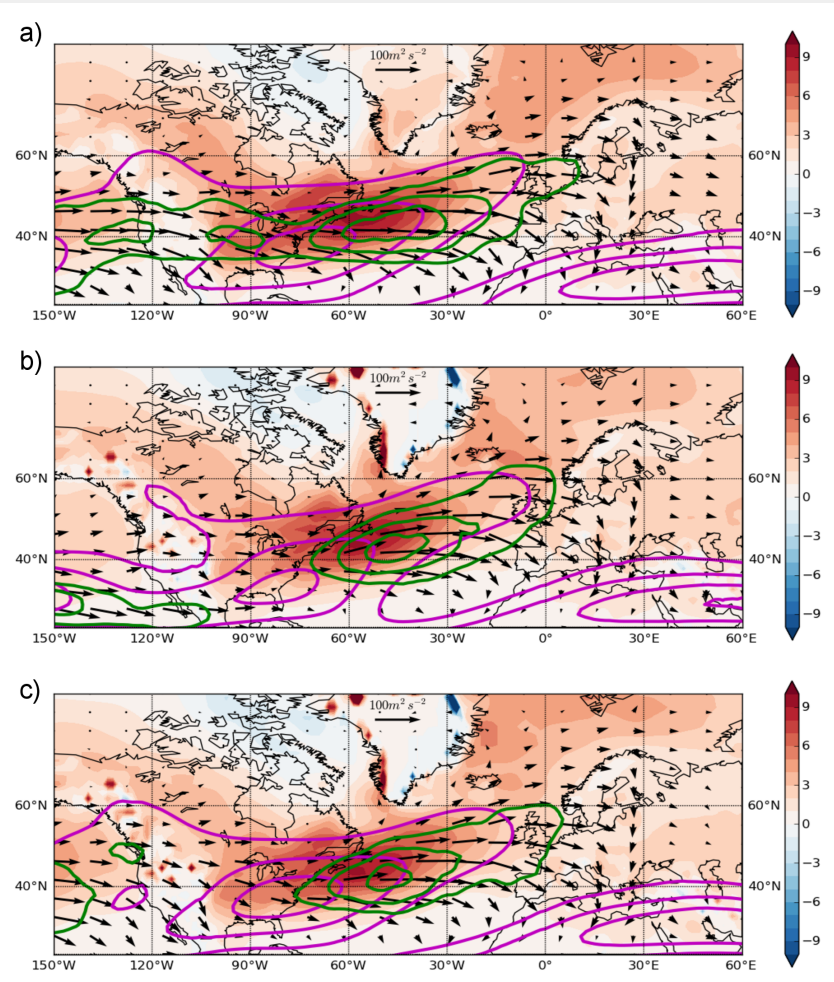

Figure 1. Jet-stream ( $u$, magenta contours) in m/s (from $20 \mathrm{~m} / \mathrm{s}$, every $10 \mathrm{~m} / \mathrm{s}$ ), the normalised third component of $E$ ( $E p$, colour shading, in $\mathrm{m} / \mathrm{s}$ ) and the magnitude of the horizontal components at $250 \mathrm{hPa}\left(|E|\right.$, green contours, from $60 \mathrm{~m}^{2} \mathrm{~s}^{-2}$ and every $30 \mathrm{~m}^{2} \mathrm{~s}^{-2}$ ) for the reanalysis $(a)$ and the model configurations ( $b$-coupled, $c$-AMIP). The arrows show the normalised $\mathrm{E}$ vectors.

\section{The jet-stream behaviour}

Fig. 1 shows the winter season jet-stream ( $u$, magenta contours) for the reanalysis (a) and the model versions ( $b$-coupled, $c$ AMIP), along with the (normalised) third component of $E$ (Ep, colour shading) and the magnitude of the horizontal components at $250 \mathrm{hPa}(|E|$, green contours). The panels generally agree with each other, though some differences are also apparent. While $E p$ generally exhibits very similar values, $|E|$ is slightly weaker for both GC2-C and GC2-A (see for example the $120 \mathrm{~m}^{2} \mathrm{~s}^{-2}$ contour at the centre of the jet). This likely has an influence on the behaviour of the jet itself, which shows a pronounced arch-shape, particularly for GC2-C, and a narrower section in its central part (see also the $30 \mathrm{~m} / \mathrm{s}$ contour). Another difference is observed further upstream in the eastern Pacific, particularly for GC2-C and compared to ERA-I, where $|E|$ is south-shifted by at least $15-20^{\circ}$. This is also evident for the mean jet, whose maximum values are shifted to the south as well. We will return to this later in section 5 . 


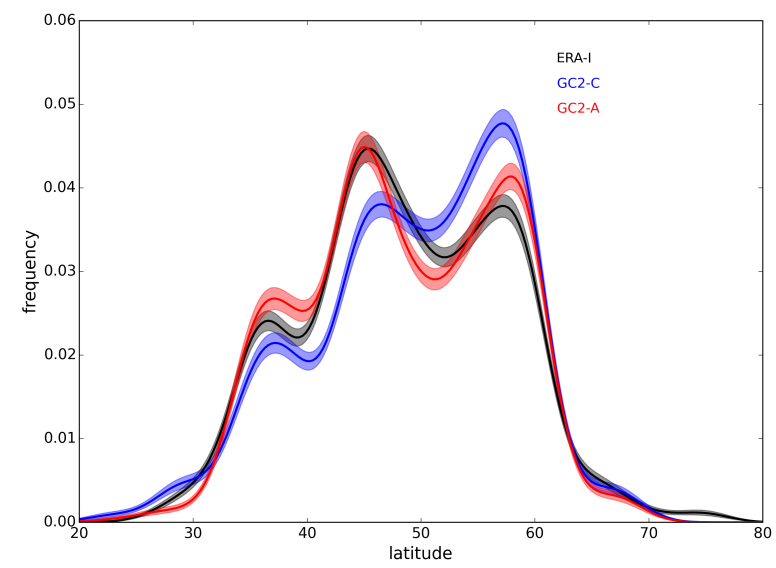

.

Figure 2. Jet latitude distribution derived following the methodology as in Wgollings et al. (2010) (see text for more details). The uncertainty ranges represent \pm 1 standard deviations from a bootstrap with 5000 trials.

1

Fig. 2 shows the winter jet latitude distribution derived following the methodology as in Woollings et al. (2010), although here the wind field used is at the single $850 \mathrm{hPa}$ level.

Note that the relatively lower occurrence of the southern peak as compared to the distribution in Woollings et al (2010) is due to the different period used (Woollings et al. 2014). The ultiple curves have been obtained using the bootstrap technique with 50 realisations, randomly selecting the daily values from the respective sample (black for ERA-I, red for GC2-C, and green for GC2-A). It is noted that GC2-C significantly stands out from the other two samples for most of the latitude range. The most noticeable difference, which confirms the bias in the previous version of the model (see Anstey et al. 2013), is in the high-latitude regime $(\mathrm{N})$, which is too populated compared to C2-A and even more compared to ERA-I. Such a positive bias in frequency is balanced by a deficit in the central position of the jet (C) and to some extent in the low-latitude (S) regime too. The results are in accordance with the differences observed in Fig. 1, if $j$ is recalled that the jet latitude is derived for the zonal average $60 \mathrm{~W}-0 \mathrm{E}$ where the arch-shape feature of the jet (as described in the paragraph above) occurs.

We can then assume that the bias of the time-mean jet as simulated in HadGEM3-GC2 is mainly due to the tendency of the jet itself to populate the $\mathrm{N}$ regime. Such a statement can be proved in different ways, one possible approach is showing the the $\mathrm{N}$ and $\mathrm{S}$ regimes are associated with jet latitudes above $51 \mathrm{~N}$ and below $39 \mathrm{~N}$, respectively. The columns in the table show the number of events lasting at least 5 days and belonging to a given regime, respectively for ERA-I, GC2-C and GC2-A. The different rows show how many of these regimes shift to the north (+), to the south (-), or remain within the same regime (=) after they have attempted a shift (i.e. if after 2-3 days they bounce back to the regime they came from). The percentages at the bottom row roughly mirror the results of Fig. 2, although they do not seem to exhibit significant differences when compared to each other, nor to show a clear bias towards the $\mathrm{N}$ regime. However, if we focus on the $\mathrm{C}$ regime, it can be noted that both the reanalysis and the two model simulations tend to prefer the $\mathrm{C}$-to-N transition. While ERA-I (and GC2-A) show a ratio of $\sim 2.7$ (2.5) (i.e., 57 (52) events shifting to the north against 21 (21) shifting to the south), GC2-C exhibits a ratio of $\sim 3.8$ (i.e. 53/14), which indicates a stronger tendency to the C-to- $\mathrm{N}$ transition at the expense of the C-to-S transition. A Monte Carlo process was used to investigate this; pooling the C-exit transitions and randomly separating into three equal subsets. This found that the chance occurrence of only 14 C-to-S transitions (as seen in GC2) can be rejected at the $90 \%$ level.

While this certainly contributes to the bias observed, it is interesting to further explore why this is the case. The positive (i.e. poleward) transitions will be analysed in detail in section 5, after the eddy flux diagnostics are introduced in section 4 and used to investigate the transitions between the jet regimes in both the reanalysis and the model versions.

\section{The regime transitions}

The jet and eddy properties in ERA-I are illustrated in Fig. 3, respectively for the $\mathrm{N}$ (panel $a$ ) and $\mathrm{S}$ (panel $b$ ) regime. The composites are the average of all days where the jet latitude is in the $\mathrm{N}$ and $\mathrm{S}$ regime, respectively. The jet is displaced to the north and south by construction (compare with Fig. 1a), and for the $\mathrm{S}$ regime it is joined to the subtropical jet over North Africa. Although both $E p$ and $|E|$ roughly follow the spatial pattern of the jet-stream, there are some important differences between the two 


\begin{tabular}{|c|c|c|c|c|c|c|c|c|c|c|c|c|}
\hline \multicolumn{5}{|c|}{ ERA-I } & \multicolumn{3}{|c|}{ GC2-C } & \multicolumn{5}{|c|}{ GC2-A } \\
\hline & S & $\mathrm{C}$ & $\mathrm{N}$ & $\mathrm{T}$ & $S$ & $\mathrm{C}$ & $\mathrm{N}$ & $\mathrm{T}$ & S & $\mathrm{C}$ & $\mathrm{N}$ & $\mathrm{T}$ \\
\hline+ & 42 & 57 & 0 & $44 \%$ & 32 & 53 & 0 & $44 \%$ & 39 & 52 & 0 & $47 \%$ \\
\hline$=$ & 1 & 18 & 10 & $12 \%$ & 1 & 12 & 8 & $11 \%$ & 0 & 7 & 8 & $6 \%$ \\
\hline - & 0 & 21 & 78 & $44 \%$ & 0 & 14 & 72 & $45 \%$ & 0 & 21 & 70 & $47 \%$ \\
\hline & $19 \%$ & $42 \%$ & $39 \%$ & 227 & $17 \%$ & $41 \%$ & $42 \%$ & 192 & $20 \%$ & $41 \%$ & $39 \%$ & 195 \\
\hline
\end{tabular}

Table 1. Table representing the jet-regime event frequency and regime transitions. The columns show the number of events lasting at least 5 days and belonging to a given regime, respectively for ERA-I, GC2-C and GC2-A. The different rows show how many of these regimes shift to the north $(+)$, to the south $(-)$, or remain within the same regime (=) after they have attempted for a shift (i.e. if after 2-3 days they bounce back to the regime they came from). The percentages are calculated over the total number of events (bottom entry under column ' $T$ ').
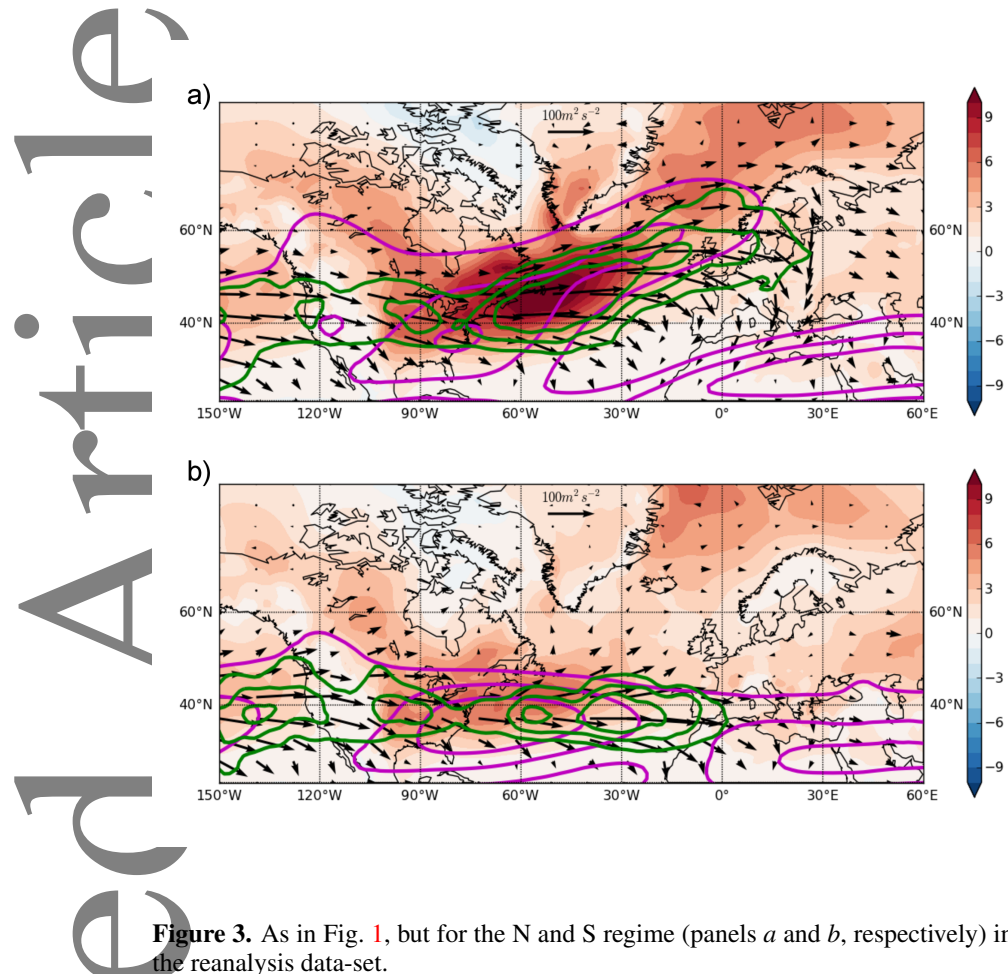

Figure 3. As in Fig. 1, but for the $\mathrm{N}$ and $\mathrm{S}$ regime (panels $a$ and $b$, respectively) in he reanalysis data-set.

regime, in accordance with the results of other studies (e.g. Novak et al. 2015), which shows that the $\mathrm{S}$ regime is associated with much weaker baroclinicity compared to the $\mathrm{N}$ regime. Secondly, $|E|$ is shifted further downstream of the jet maximum for the $S$ gime, also exhibiting symmetric propagation out of its core (see the direction of the arrows in figure). For the $\mathrm{N}$ regime, the direction of propagation is mainly southward. This difference has already been observed to play a crucial role in the jet persistence for the two regimes. Barnes and Hartmann (2010) demonstrated that the lack of poleward wave propagation and breaking on the northern flank of the jet is the main cause for the short residency time characterising the positive NAO state.

To further understand and better quantify such differences, $E p$ and $|E|$ have been calculated around the jet-axis for all events belonging to the $\mathrm{S}, \mathrm{C}$ and $\mathrm{N}$ regimes. The events have days (i.e. those that remain within the same latitude range for a minimum of 5 days). This condition just removes some rare very brief jet shifts which are considered unphysical (Woollings et al. 2010). The $u$ component of the wind at $850 \mathrm{hPa}$ has been used to identify the jet latitude, i.e. the maximum value of the field for each point in longitude within the sector 90W-0E. Ep and $|E|$ are retained up to $20^{\circ}$ north and south of the given jet latitude, so that their values are always centred around the jet latitude itself. As the identification of the longitudinally-varying daily jet latitude tends to be quite noisy, the events belonging to a given regime have been averaged together before the identification of the wind maxima.

Fig. 4 illustrates the time evolution of the transition from the $\mathrm{C}$ regime to the north ( $\mathrm{C}$-to-N - panels $a$ and $b$ ) and to the south (C-to-S - panels $c$ and $d$ ) in ERA-I. Panels $a$ and $c$ show Ep (colour shading) and $|E|$ (black contours), while the colour shading in panels $b$ and $d$ represents $E d$ (see section 2 for the details). The three diagnostics have been zonally averaged beforehand. Taking Fig. 1 as reference, $E p$ has been averaged between 90-30W, whereas $|E|$ and $E d$ have been averaged between $75-15 \mathrm{~W}$. Note that for comparison the climatology of each diagnostic is shown in a narrow bar immediately to the right of each panel. Both $E p$ and $|E|$ are much larger for the C-to-N transition, with highest values at the time of transition (day 0), while they are very weak for the other case. The direction of the momentum fluxes $(E d)$ is shown in panels $b$ and $d$. For the days immediately before and after the C-to-N transition, the wave propagation is mainly equatorward and on the southern flank of the jet. This is contrasted by the C-to-S transition, where the wave propagation is weaker in magnitude and present on either 

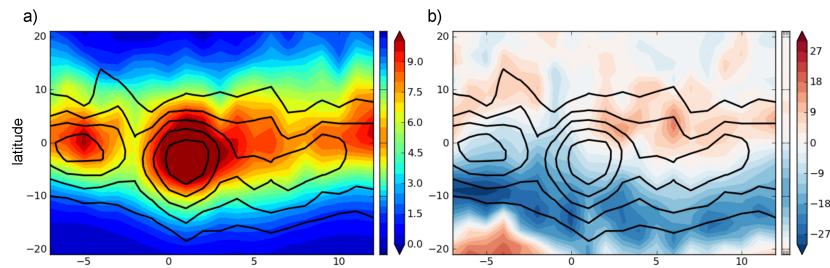

c)

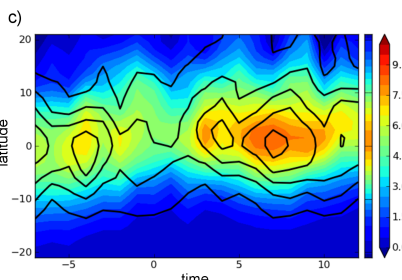

d)

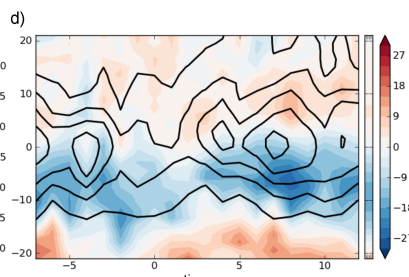

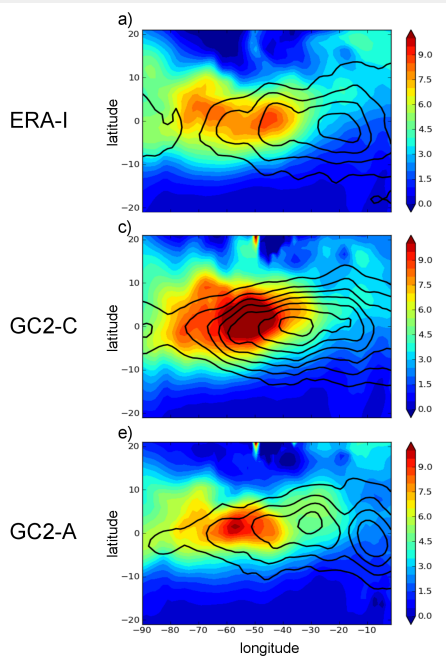

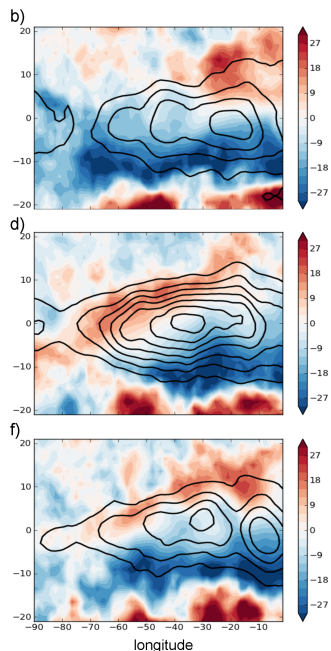

Figure 4. Time evolution (x-axis) of the transition from the $\mathrm{C}$ regime to the north (panels $a$ and $b$ ) and to the south (panels $c$ and $d$ ) in ERA-I. Panels $a$ and $c$ show Ep (colour shading) and $|E|$ (black contours), while the colour shading in panels $b$ and $d$ represents $E d$ (see section 2 for the details). The climatology of each diagnostic is given in narrow bar immediately to the right of each panel.
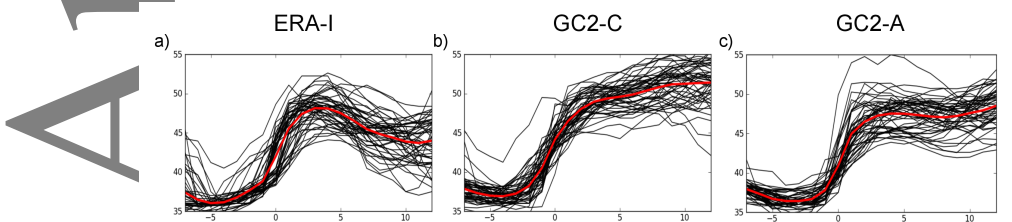

5. Time evolution (x-axis in days) of the jet latitude on exit from the $\mathrm{S}$ regime (day 0) in ERA-I, GC2-C and GC2-A (left, central and right panels, respectively). The thick red line illustrates the average signal, whereas the thin black lines represent the spread itself (i.e. each line is a single realisation of the bootstrap (a)thod).

against the climatology of $E p$ and $E d$, the transitions to the $\mathrm{N}$ or $\mathrm{S}$ regimes can be interpreted respectively as an anomalous increase or decrease of the eddy heat fluxes, accompanied by an anomalously high or low activity in the wave propagation out of the jet, particularly for the equatorward component on its C southern flank. For example, the period during the onset of the S regime is marked by strongly weakened equatorward wave propagation, consistent with the role of cyclonic wave-breaking in the onset of these events (e.g Benedict et al. 2004).

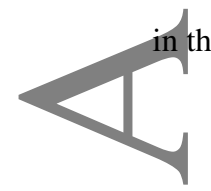

\section{The northern regime bias}

The tools used in section 4 can be used to investigate the bias affecting the coupled version of HadGEM3-GC2, namely the prevalence of the northern jet regime. The jet transition to high latitudes will be explored separately for the $\mathrm{S}$ and $\mathrm{C}$ regime. Fig. 5 shows the jet shift from the $\mathrm{S}$ regime in ERA-I, GC2-C and GC2-A This article is protected by copyright. All rights reserved.
Figure 6. Longitude-latitude maps of $E p, E d$ (colour shading in the left and right column, respectively) and $|E|$ (black contours) calculated as the three day average before the jet exits from the $\mathrm{C}$ regime. The first, second and third row are respectively for ERA-I, GC2-C and GC2-A

The latitude shift in ERA-I (shown in Fig. 5a) clearly indicates that the jet moves back equatorward after it reaches its maximum at $\sim$ day 4 . In contrast, in GC2-C the jet keeps moving to the north and it reaches its highest latitude at day 11 (panel $b$ ), more than $5^{\circ}$ higher (on average) than in the reanalysis. This is a significant difference, and it accounts, together with the statistics shown in table 1, for the northern bias of the jet in GC2-C. There is some evidence that the transient eddy heat fluxes are biased high during these transitions in GC2-C, however this signal is noisy and has low statistical significance. We focus instead on the exit from the $\mathrm{C}$ regime which shows a similar, but much clearer signal.

Similar to Fig. 5 we analysed the evolution of the jet latitude on exit from the $\mathrm{C}$ regime. The results (not shown) do not exhibit a bias in the latitudes, as in the $\mathrm{S}$ regime case. However, there is a clear bias, as in Table 1 for the model transitions to be too often to the north as opposed to the south. Fig. 6 shows a longitude/latitude map of the average of the three diagnostics (i.e. $E p,|E|$ and $E d$ ) for the three days prior to this transition, as a composite of all the events belonging to the $\mathrm{C}$ regime. (Note that the $\mathrm{C}$ regime in general exhibits patterns which are similar to the climatology but more sharply defined). ERA-I, GC2-C and GC2-A are on the top, middle and bottom row respectively. This shows what happens before the jet exits from the $\mathrm{C}$ regime, in order to identify any precursor to the transition. Indeed, GC2-C shows overly strong eddy flux activity (denoted by the large values in $E p$ and $|E|)$. This behaviour is unique to the coupled 


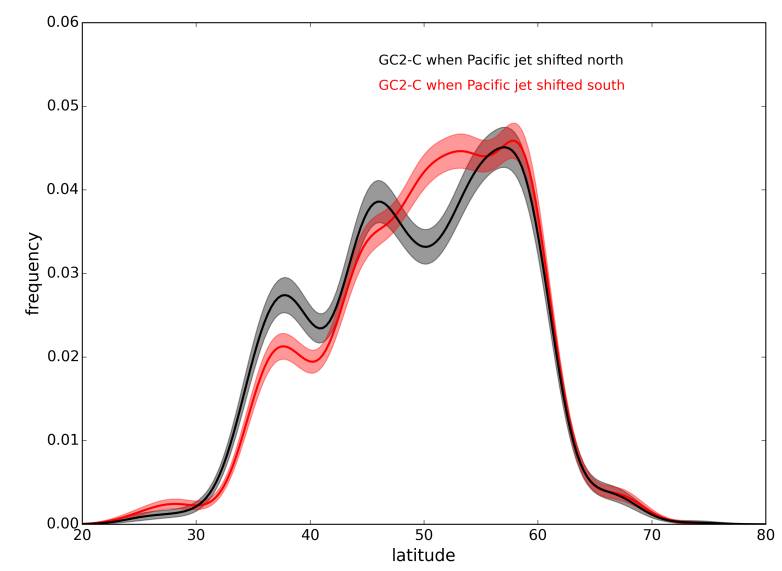

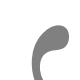

Figure 7. Jet latitude distribution for GC2-C, calculated as in Fig. 2 (see text more details). The black and red curves represent the latitude distribution of the Atlantic jet stream when the Pacific jet is shifted to the north and to the south, respectively. The shading indicates the \pm 1 standard deviation range from a bootstrap with 5000 trials.

( )

version of HadGEM3-GC2, both ERA-I and GC2-A exhibit weaker heat fluxes upstream and much weaker momentum fluxes further downstream. This result is even more striking if compared with the time-mean values of the eddy diagnostics in Fig. 1, which are broadly of the same magnitude for ERA-I and GC2-C. GC2-C is associated with a relatively weak equatorward wave propagation (panel $d$ ). This is also evident in the exit from the $\mathrm{S}$ regime, though again with low significance. Compared to ERA-I and GC2-A (panel $b$ and $f$ ), negative $E d$ values are confined downstream within the Atlantic sector, whereas for the other two datasets the southward propagation extends across the whole basin.

We now look at other aspects of the coupled model bias to dentify factors which could lead to the biases in the Atlantic jet. One possibility is related to the unrealistic flow across North America which was mentioned in section 2 (see Fig. 1b). This southward-biased jet is likely associated with errors in the divergent flow at upper levels in the tropical East Pacific (not shown). It is well known that a shift in the Pacific jet can potentially modify the entrance of the jet stream over the Atlantic sector. Following the results of Franzke et al. (2004), we expect that a south-shifted jet over the Pacific Ocean enhances the anticyclonic curvature on the southern flank of the Atlantic jet. Franzke et al demonstrated that a southward shifted Pacific storm track encourages transient eddies to enter the Atlantic sector on the southern, anticyclonic side of the jet, favouring This article is protected by copyright. All rights reserved. anticyclonic wave breaking there. This situation favours enhanced warm air advection in the Gulf Stream region and the associated south-westerly flow prior to and in correspondence with the exit from the $\mathrm{C}$ regime, and could potentially explain the eddy heat flux bias in GC2-C.

As a test of this hypothesis, an index has been created which measures the meridional oscillations of the downstream end of the Pacific jet stream. It is a difference of the $u$ component of the wind at $250 \mathrm{hPa}$, between $(165 \mathrm{~W}, 40 \mathrm{~N})$ and $(165 \mathrm{~W}, 27 \mathrm{~N})$. This index is used to identify events when the jet is shifted north (index $>-20 \mathrm{~m} / \mathrm{s}$ ) and south (index $<-20 \mathrm{~m} / \mathrm{s}$ ). Fig. 7 shows the Atlantic jet latitude distribution from the coupled model simulation conditioned on the state of the Pacific jet. When the Pacific jet is shifted north in this simulation the Atlantic jet distribution is weighted south, with an increased occurrence of the $\mathrm{S}$ regime and reduced occurrences at higher latitudes. Fig. 1 shows that the wind and eddy biases in the East Pacific and across North America are partially improved in the atmosphereonly simulation forced with observed SSTs. Hence it may be via the Pacific sector that the reduction in SST bias has affected the Atlantic. To summarise, when the Pacific jet is more realistic, the Atlantic jet distribution is improved. This is a clearly significant result and in the rest of this section we investigate the effects this has on the transient eddies in the Atlantic, following the results of Franzke et al. (2004).

A composite of all the $\mathrm{C}$ regime events in the reanalysis has been created for the 3 days prior to the regime exit, as illustrated in Fig. $8 a$. The wind at the upper levels is shown there (magenta contours), along with the anomalies against the climatology for $E p$ (colour shading) and the wind at $850 \mathrm{hPa}$ (arrows). The Pacific wind index has been subsequently applied to condition the events to the north-shifted phase (panel $c$ ) and the south-shifted phase (panel $e$ ) of the Pacific jet. In the latter, the Pacific jet behaves approximately like its counterpart in the GC2-C run. This is confirmed by the large anomalies in $E p$ and the low level winds there, as shown in Fig. 8e. The impact on the Atlantic jet is in the sense of an enhanced tilt along the south-west to north-east direction, confirmed by the anticyclonic curvature of the low level wind (see the arrows in figure). However, this is not 
a)

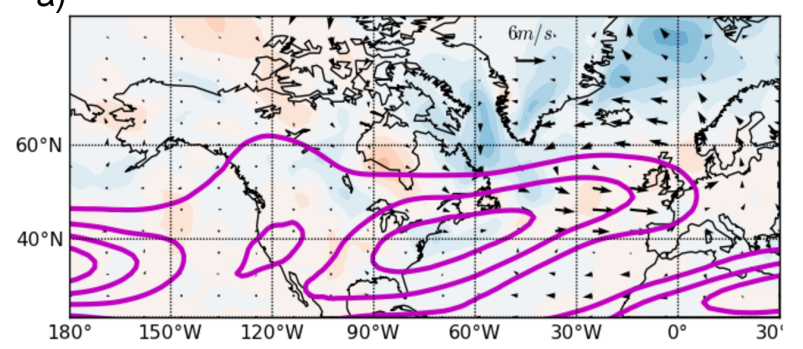

c)

ERA-I, N-shifted PAC

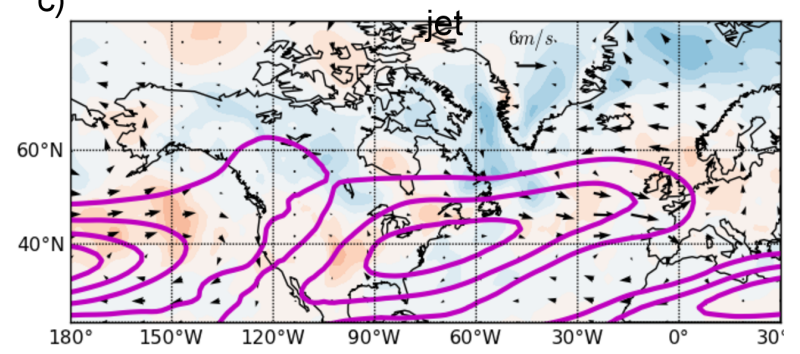

e)

ERA-I, S-shifted PAC jet

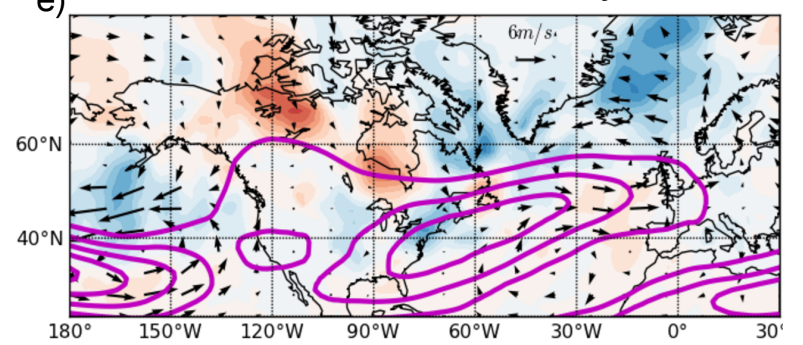

b)

GC2-C, all events

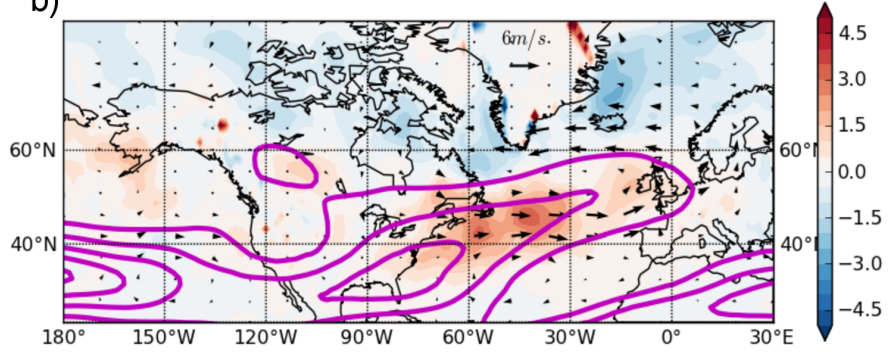

d)

GC2-C, N-shifted PAC jet
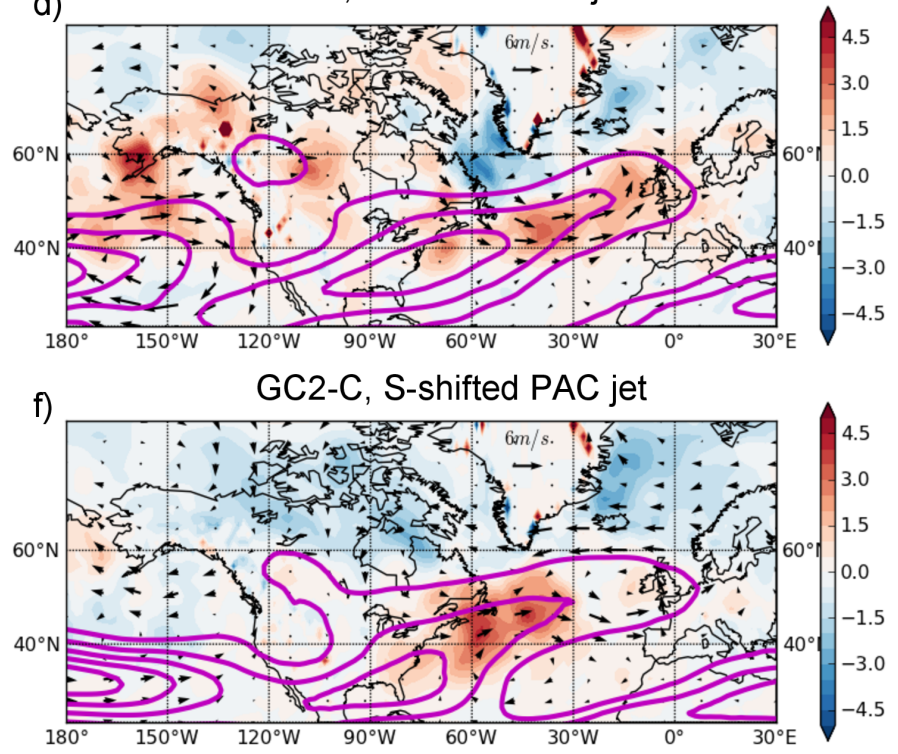

Figure 8. Composites of the $\mathrm{C}$ regime events, averaged over the three days prior to the regime exit, for ERA-I (left column) and GC2-C (right column). The fields plotted are $u$ at $250 \mathrm{hPa}$ (magenta contours, from $20 \mathrm{~m} / \mathrm{s}$ and every $10 \mathrm{~m} / \mathrm{s}$ ), and the anomalies of $E p$ (colour shading) and the wind at $850 \mathrm{hPa}$ (arrows). Panels $c$ and $d$ show the same composites, but conditioned to a north-shifted Pacific jet. Panels $e$ and $f$ are for the events conditioned to a south-shifted Pacific jet.

1

accompanied by larger heat fluxes at low levels (i.e. absence of

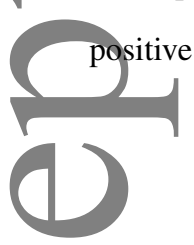

If the same procedure is applied to the GC2-C run, as in the right-hand side of Fig. 8, the Atlantic sector response is more sensitive to the changes in the position of the Pacific jet. When the Pacific jet bias is decreased (as in panel $d$ ), the Atlantic eddydriven jet better resembles its counterpart in ERA-I (compare panels $c$ and $d$ ), and the strong tilt that characterises its shape off the coasts of North America is partially adjusted (compare for example panels $b d$ in figure). In this case the positive anomalies in $E p$ as identified in Fig. $6 c$ are also partially lost, and confined to the downstream end of the Atlantic jet. It is only when the Pacific jet moves towards its climatology (and the south-shifted bias is introduced once again, as in Fig. $8 f$ ) that the anticyclonic curvature is activated over the upstream Atlantic basin, leading

to anomalously strong heat fluxes over the Gulf Stream region at This article is protected by copyright. All rights reserved.

\section{0-70W (denoted by the positive values in $E p$ ).}

The fact that the atmosphere-only version of the model did not show the positive heat flux bias to nearly the same extent (see panels $c$ and $e$ in Fig. 6) suggests that the heat flux behaviour may be associated with the SSTs and the anomalous gradients they generate. In other studies it has been demonstrated that an SST bias can be detrimental to the simulation of the largescale dynamics over the Euro-Atlantic sector (Scaife et al. 2011; Davini et al. 2013; OReilly et al. 2015). The longitude of the Ep maximum prior to the jet exit from the $\mathrm{C}$ regime in the $\mathrm{GC} 2-\mathrm{C}$ run is around 50-70W, which is exactly over the Gulf Stream, close to the North American coast. In the GC2-C SST anomalies (see Fig. S2 in the supplementary material) it is observed that the Gulf Stream is in fact too warm, which potentially makes the temperature gradient between the coastal Atlantic and cold North America too large. It then appears that a combination of factors might be at play in such a scenario. First, the Pacific bias forces 
the Atlantic jet to an anomalous anticyclonic curvature, which places it along the North American coast and aligned with the Gulf Stream region. Second, the SST bias present there triggers the anomalous activity in the heat flux, which is found to be responsible for the northern regime bias.

\section{Conclusions}

This paper has evaluated the performance of the latest operational climate model version in use at the Met Office (HadGEM3-GC2) in simulating the wintertime eddy-driven jet behaviour over Euro-Atlantic sector. This has been done using a processbased analysis, recognising that the jet stream variability is argely determined by the interactions between higher frequency, synoptic-scale processes and the larger-scale dynamics. Several studies have already shown that the eddy fluxes are central to such an analysis, here we demonstrate they are also a valuable tool for the explanation of the model's bias in describing the tri-modal behaviour of the Atlantic jet stream. Overall, it is shown that the transition to higher latitudes is preceded and accompanied by arge eddy heat fluxes, in accordance to the results in Novak et al. (2015). This is followed by a strong equatorward wave activity anomaly, which in turn enhances the poleward momentum flux at upper levels (see also Fig. 7 in Thompson and Birner 2012). In contrast, the jet shift to lower latitudes is preceded and accompanied by anomalously low eddy activity, while the wave propagation is present on either flank of the jet, once again in accordance with the barotropic theory of the eddy-mean flow feedback (e.g. Fig. 6 in Yu and Hartmann 1993).

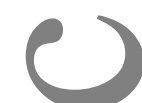

The bias in the time-mean jet (at least in the coupled model version) has been associated with an over-populated $\mathrm{N}$ regime compared to the reanalysis. Interestingly, HadGEM3-GC2 shares the same bias with the ECMWF operational ensemble forecasts (Leutbecher and Palmer 2008), which have a tendency to drift towards too much 'Atlantic ridge' (see Ferranti et al. 2014), which roughly equates to too much $\mathrm{N}$ regime occurrence. In the case of HadGEM3-GC2, this is mainly down to two reasons. One is the tendency of the jet to favour too often the $\mathrm{N}$ regime once exiting from the $\mathrm{C}$ state. The other is the overly long residence This article is protected by copyright. All rights reserved. that both behaviours can be explained by the large eddy heat fluxes (the third component of the E-vector) in GC2-C, which are in turn associated with a strong upper level momentum flux (the horizontal component of the E-vector).

The exit of the Pacific jet is too far south in the coupled model GC2-C and this, along with the warm biased SSTs over the Gulf Stream region may be acting together in fostering the anomalous activity in the low level eddy heat fluxes, which in turn generate the observed bias in the location of the eddy-driven jet. To further test this hypothesis more work is ongoing, with targeted model experiments to investigate the role of local SST biases versus effects from outside the North Atlantic. The results of such experiments and their analysis will be discussed in a future paper.

\section{Acknowledgement}

This work was supported by the Joint UK DECC/Defra Met Office Hadley Centre Climate Programme (GA01101). We would like to thank two anonymous reviewers for their insightful comments which have helped to improve the paper.

\section{The $E$-vector, its magnitude and its divergence}

Throughout the manuscript $|E|$ has been used to describe the momentum flux instead of its divergence $(\operatorname{div}(E))$. In Hoskins et al. (1983) it is explained that $E$ may be considered as an effective westerly momentum flux. Its generation (divergence) can be thought as a tendency to increase the westerly mean flow, whereas its destruction (convergence) is associated with a decrease of the westerly mean flow. Despite this being generally used in the literature, we opted for the E-vector magnitude, which is somehow an indirect measure compared to the former, but it can still be easily interpreted and it is much less noisy (as the derivative is avoided). An example of this is found in Hoskins et al. (1983) (their Fig. 6), where the Pacific and Atlantic storm tracks during the winter season 1979-80 are analysed using the high- and low-pass eddies and the E-vector horizontal 


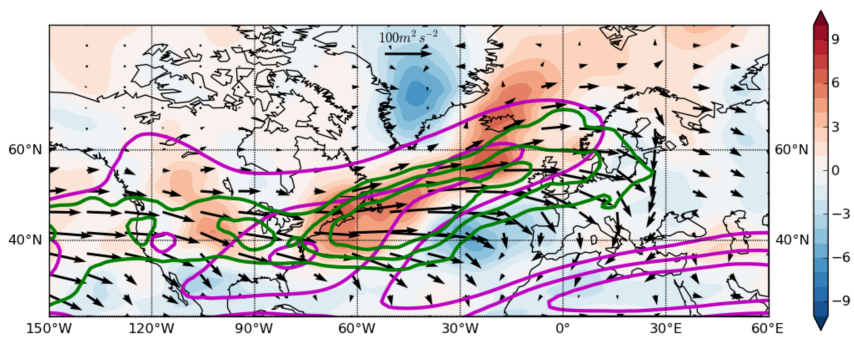

Figure 9. Jet-stream ( $u$, magenta contours) in m/s (from $20 \mathrm{~m} / \mathrm{s}$, every $10 \mathrm{~m} / \mathrm{s}$ ), the normalised $\operatorname{div}(E)$ (colour shading, in $\mathrm{m} / \mathrm{s}$ ) and the magnitude of the horizontal components of $E$ at $250 \mathrm{hPa}\left(|E|\right.$, green contours, from $60 \mathrm{~m}^{2} \mathrm{~s}^{-2}$ and every 30 $\mathrm{m}^{2} \mathrm{~s}^{-2}$ ) for the $\mathrm{N}$ regime in the reanalysis.

components.

To further clarify how the two measures are related, Fig. 9 illustrates the jet in its $\mathrm{N}$ regime (the magenta contours are the wind velocity $u$ ) along with $|E|$ and its divergence (in green contours and colour shading, respectively). The latter has been normalised as in Brayshaw et al. (2008) to allow comparison with the third component of the E-vector (to be noted that the colorbar is the same as that in Fig. 1). It is observed that $|E|$ is slightly downstream of $\operatorname{div}(E)$, however it has also been noticed (see section 3 ) that $|E|$ has been zonally averaged for most of the figures produced (apart from Fig. 6), which makes the longitude shift with $\operatorname{div}(E)$ essentially insignificant. The largest difference is the meridional shift between the two, with the maximum values of $E \mid$ located on average to the south of the jet core and in between the positive/negative dipole in $\operatorname{div}(E)$. This is not surprising, as $\operatorname{div}(E$ measures the horizontal gradient of the E-vector, but this slight latitude shift should be born in mind when interpreting the results. Furthermore, the third diagnostic introduced in the paper $E d$ ) not only acts as a proxy for the wave propagation (and elative momentum flux), but it also helps detecting - along with $|E|$ - where the convergence of $E$ should be, whether to the north or to the south of the jet. For example, if Fig. $4 a$ were integrated along time (the x-direction) and compared to Fig. 9, it would be noticed that $|E|$ points almost exclusively equatorward, which indicates that the $E$ sink region is on the southern flank of the jet.

\section{References}

Anstey JA, Davini P, Gray LJ, Woollings TJ, Butchart N, Cagnazzo C, Christiansen B, Hardiman SC, Osprey SM, Yang S. 2013. Multi-model analysis of northern hemisphere winter blocking: Model biases and the

This article is protected by copyright. All rights reserved. role of resolution. Journal of Geophysical Research: Atmospheres 118(10): 3956-3971.

Barnes EA, Hartmann DL. 2010. Dynamical feedbacks and the persistence of the nao. Journal of the Atmospheric Sciences 67(3): 851-865.

Barnes EA, Hartmann DL, Frierson DM, Kidston J. 2010. Effect of latitude on the persistence of eddy-driven jets. Geophysical research letters 37(11).

Benedict JJ, Lee S, Feldstein SB. 2004. Synoptic view of the north atlantic oscillation. Journal of the atmospheric sciences 61(2): 121-144.

Brayshaw DJ, Hoskins B, Blackburn M. 2008. The storm-track response to idealized sst perturbations in an aquaplanet $\mathrm{gcm}$. Journal of the Atmospheric Sciences 65(9): 2842-2860.

Collins W, et al. 2008. Evaluation of the hadgem 2 model. Hadley Cent. Tech. Note 74.

Davini P, Cagnazzo C, Fogli PG, Manzini E, Gualdi S, Navarra A. 2013. European blocking and atlantic jet stream variability in the ncep/ncar reanalysis and the cmcc-cms climate model. Climate Dynamics : 1-15.

Dee D, et al. 2011. The era-interim reanalysis: Configuration and performance of the data assimilation system. Quarterly Journal of the Royal Meteorological Society 137(656): 553-597.

Duchon CE. 1979. Lanczos filtering in one and two dimensions. Journal of Applied Meteorology 18(8): 1016-1022.

Ferranti L, Corti S, Janousek M. 2014. Flow-dependent verification of the ecmwf ensemble over the euro-atlantic sector. Quarterly Journal of the Royal Meteorological Society.

Franzke C, Lee S, Feldstein SB. 2004. Is the north atlantic oscillation a breaking wave? Journal of the atmospheric sciences 61(2): 145-160.

Franzke C, Woollings T, Martius O. 2011. Persistent circulation regimes and preferred regime transitions in the north atlantic. Journal of the Atmospheric Sciences 68(12): 2809-2825.

Gerber EP, Vallis GK. 2007. Eddy-zonal flow interactions and the persistence of the zonal index. Journal of the Atmospheric Sciences 64(9): 3296-3311.

Hannachi A, Barnes EA, Woollings T. 2013. Behaviour of the winter north atlantic eddy-driven jet stream in the cmip3 integrations. Climate dynamics 41(3-4): 995-1007.

Hoskins BJ, James IN, White GH. 1983. The shape, propagation and meanflow interaction of large-scale weather systems. Journal of the atmospheric sciences 40(7): 1595-1612.

Leutbecher M, Palmer TN. 2008. Ensemble forecasting. Journal of Computational Physics 227(7): 3515-3539.

Lorenz DJ, Hartmann DL. 2001. Eddy-zonal flow feedback in the southern hemisphere. Journal of the atmospheric sciences 58(21): 3312-3327.

Mahlstein I, Martius O, Chevalier C, Ginsbourger D. 2012. Changes in the odds of extreme events in the atlantic basin depending on the position of the extratropical jet. Geophysical Research Letters 39(22).

Novak L, Ambaum MH, Tailleux R. 2015. The life cycle of the north atlantic storm track*. Journal of the Atmospheric Sciences 72(2): 821-833. 
OReilly CH, Minobe S, Kuwano-Yoshida A. 2015. The influence of the gulf stream on wintertime european blocking. Climate Dynamics In Press.

Scaife AA, Copsey D, Gordon C, Harris C, Hinton T, Keeley S, O’Neill A, Roberts M, Williams K. 2011. Improved atlantic winter blocking in a climate model. Geophysical Research Letters 38(23).

Taylor KE, Stouffer RJ, Meehl GA. 2012. An overview of cmip5 and the experiment design. Bulletin of the American Meteorological Society 93(4): 485-498.

Thompson DW, Birner T. 2012. On the linkages between the tropospheric isentropic slope and eddy fluxes of heat during northern hemisphere winter. Journal of the Atmospheric Sciences 69(6): 1811-1823.

Trigo RM, Osborn TJ, Corte-Real JM, et al. 2002. The north atlantic oscillation influence on europe: climate impacts and associated physical mechanisms. Climate Research 20(1): 9-17.

Walters D, et al. 2014. The met office unified model global atmosphere. in preparation .

Williams K, et al. 2014. The met office global coupled model 2.0 (gc2) configuration. submitted to Geoscientific Model Development .

Woollings T, Czuchnicki C, Franzke C. 2014. Twentieth century north atlantic jet variability. Quarterly Journal of the Royal Meteorological Society 140(680): 783-791.

Woollings T, Hannachi A, Hoskins B. 2010. Variability of the north atlantic eddy-driven jet stream. Quarterly Journal of the Royal Meteorological Society 136(649): 856-868.

Yu JY, Hartmann DL. 1993. Zonal flow vacillation and eddy forcing in a simple $\mathrm{gcm}$ of the atmosphere. Journal of the atmospheric sciences 50(19): 32443259 .

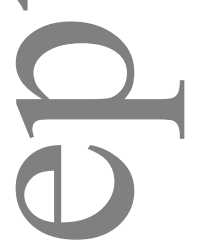

()

C)

This article is protected by copyright. All rights reserved. 